\title{
Peter Tschmuck: The economics of music, 2nd edition
}

\section{Agenda Publishing, Newcastle, 2021}

\section{Patrik Wikstrom ${ }^{1}$}

\section{Published online: 7 February 2022}

(c) The Author(s), under exclusive licence to Springer Science+Business Media, LLC, part of Springer Nature 2022

The music industry is a dynamic and complex phenomenon that provides ample opportunity for fruitful economic analysis. Music is regularly covered by studies on the economics of the wider cultural economy, but there are few books that focus exclusively on the economics of music. Peter Tschmuck's "The economics of music" in 2017 is; however, one rare exception. The book is published by Agenda Publishing and belongs to their series "The economics of big business" where other volumes cover businesses such as airlines, arms, and fishing. In 2021, a second edition was published. There were definitely good reasons to update this book, since over the second half of the 2010s, the recorded music industry has grown by $50 \%$ and its logic has been fundamentally transformed. This transformation, as well as the growth, was primarily driven by music streaming platforms (e.g. Apple Music, Spotify and Deezer), which expanded their combined share of the recorded music revenues from $20 \%$ in 2015 to $62 \%$ in 2020 .

One should not underestimate the challenge of keeping a volume on "the economics of music" up to date in such turbulent times, and Tschmuck, who teaches at the University of Music and Performing Arts, Vienna, deserves recognition and admiration for giving it a go. The publisher explains that the second edition includes a new analysis of the impact of the Covid-19 pandemic, "as well as trends in the industry, such as the increasing dominance of tech companies and big data". So, how well is the book able to capture the economic workings of the contemporary music industry?

As is commonplace in industry overviews, the introductory chapter discusses the definition of the music industry, its boundaries and sub sectors. The frameworks of the music industry and the wider music economy presented in this chapter are useful overviews of the complexities of the music business.

Chapter one provides a brief historic overview of the music business. There is a plethora of such accounts in other volumes about the music industry, but Tschmuck

Patrik Wikstrom

patrik.wikstrom@qut.edu.au

1 Queensland University of Technology, Brisbane, Australia 
provides a slightly different take by bringing a Central European perspective to the table. This is refreshing as most other similar accounts tend to prioritise the music industries in Anglophone markets. It is challenging to write a cohesive history of an industry where national markets are as idiosyncratic as in the music industry, and this chapter would have benefitted by at least acknowledging that the history and characteristics of music markets vary considerably between countries. Also, nonWestern markets have grown faster than most mature markets over the past decade but even the most significant non-Western markets, such as China and Japan, are barely mentioned.

In chapters two and three, the author uses economic theory to explain the fundamental logic and idiosyncrasies of the contemporary music economy. He analyses music as an economic good, and then moves on to an economic analysis of music copyright. These chapters read well, and serve both as an effective introduction to a number of fundamental economic concepts and to the basic functioning of the music economy.

The chapters allow economic theory to lead the narrative and use the music business as the context to exemplify those concepts, rather than the other way around. This structure makes the chapters read like an economics textbook rather than a book about the music economy. The music industry examples and Tschmuck's careful explanation of concepts provides an effective introduction to microeconomics, even for students who do not consider the music industry as their main area of interest.

The author often turns to CDs for examples in these and other chapters, which indicates that the new edition retains much of the contents from the first edition. While the examples are useful to elucidate the theoretical concepts, the examples feel somewhat outdated in the 2020s, as the CD no longer is a relevant distribution format. According to the latest industry data, CD sales contributed merely $12.7 \%$ to the total recorded music revenues in 2020, and more than half of that sales took place in just two markets-South Korea and Japan.

The next three chapters cover the main sectors of the music industry-music publishing, recorded music and live music. Each chapter follows the same structure, consisting of an overview of the functions of the industry sector and an overview of the structure of its market. These chapters continue to emphasise physical distribution and the logics of the pre-streaming music economy. Topics that are essential for understanding the economics of the contemporary music industry are missing, such as the economics of music streaming platforms; the logic of royalty pooling; models for repatriation of royalties to composers and performers; etc. But the overviews are still informative and useful introductions to the three sectors and their key functions, players, trends and statistics.

Chapter 7 is mainly focused on markets for music licensing, but the chapter also gives a brief overview of how some music artists can develop their brands to sign lucrative sponsorship deals or license their brands for merchandising. The introductions to these business areas are useful and effective and Tschmuck notes how all these secondary music markets provide opportunities to artists and composers to 
add significant revenue streams to their businesses. In chapter 8 , Tschmuck expands on the topic of how the music workers' revenue streams have become increasingly diverse and complex over the past decades and provides a relevant and interesting account of the labour markets for superstars as well as for the less successful musician, composer or performer. This is an important change of the music industry logic over the past decades and Tschmuck covers this development as well as its impacts on music industry actors.

The two final chapters of the book are mainly concerned with the digital music business. In chapter 9 , Tschmuck reflects on whether music streaming services are cannibalizing or complementing music downloads and CD sales. The transformation of the recorded music industry since 2015 clearly shows that the answer to this question is a resounding "Yes", and in 2022, this discussion does feel somewhat moot. The chapter moves on to a section titled "The economics of music streaming", which is primarily concerned with the viability of music streaming as a business model. Tschmuck concludes that music streaming is a challenging business and predicts a market consolidation with bankruptcies, mergers and acquisitions. This is an important but controversial claim, but indeed, the prediction may very well be correct. However, even if the market for music streaming platforms will consolidate, there is no doubt that the streaming platform's current domination of music distribution will continue. The key question today is not about the viability of these business models, but rather what the domination of these music streaming services means for music creatives, organisations and institutions. Tschmuck states at the end of the book that "the income from music streaming for artists is low and even superstars cannot afford living from streaming payouts alone." (p. 217). This is a highly debatable statement since there is ample anecdotal evidence showing the opposite. It would have been useful to have a more empirically grounded analysis to support the claim.

The book provides a useful introduction to the pre-streaming music economy, and readers will no doubt have a better understanding of the music economy after reading. The book will continue to serve as an excellent foundation and a call for further studies of the dynamics and complexities of the contemporary music economy. There are plenty of research opportunities waiting for scholarly attention. For instance, what is the impact of streaming services on the commercial success of different types of music? What does it mean that music rights are increasingly traded as financial assets? How do algorithmically curated playlists transform the logics of the music economy? How do different models for repatriating royalties from streaming services to rights holders change the allocation of value between composers and performers? As the music economy keeps growing and transforming, these and many other stimulating research questions will become increasingly relevant and provide fruitful prospects to make important contributions to the field.

Publisher's Note Springer Nature remains neutral with regard to jurisdictional claims in published maps and institutional affiliations. 